\title{
“Fácies" do trabalho de Enfermagem na assistência à criança hospitalizada
}

\section{"Faces" of the work of Nursering in assistance to hospitalized chilfre}

\author{
“Facets" del trabajo de Enfermaje en asistencia a niños hospitalizados
}

\author{
Daniela Dias Quirino', Neusa Collet"
}

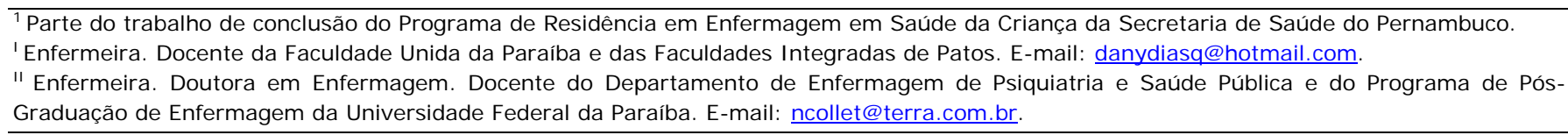

\section{RESUMO}

No cuidado à criança hospitalizada devemos buscar a construção de um projeto terapêutico compartilhado e centrado na criança e sua família. O objetivo deste estudo foi apreender a organização do processo de trabalho da equipe de enfermagem no cuidado a crianças hospitalizadas. Pesquisa exploratória de natureza qualitativa cuja coleta de dados foi realizada em um hospital filantrópico do estado de Pernambuco por meio da entrevista semi-estruturada nos meses de abril e maio de 2007. Os sujeitos do estudo foram enfermeiras, técnicas e auxiliares de enfermagem que aceitaram participar da pesquisa. Os resultados apontam que o modo de organização do trabalho da equipe de enfermagem está centrado em procedimentos e fragmentação de tarefas. A insuficiência de recursos humanos, sobrecarga de trabalho, superlotação, insatisfação e desmotivação profissional são determinantes que contribuem para esse modelo assistencial. Esses aspectos são agravantes de problemas para a criança-família e para os profissionais, gerando medo, ansiedade, angústia, dor, podendo desencadear sofrimento psíquico. Para a superação desse enfoque urge a adoção de tecnologias de cuidado pautadas pela integralidade, vínculo, responsabilização. A construção da assistência de enfermagem à criança hospitalizada exige que os profissionais reflitam suas práxis, reorganizando seus processos de trabalhos a partir do trabalho coletivo e humanizado.

Descritores: Criança hospitalizada; Assistência de Enfermagem; Enfermagem pediátrica; Trabalho.

\section{ABSTRACT}

In care of hospitalized children we should seek to build a therapeutic project shared and focused child and his family. This study aimed to understand the organization of the work of the nursing team in caring for hospitalized children. An exploratory research of qualitative nature of data collection, which was held in a charitable hospital in the state of Pernambuco through semi-structured in April and May of 2007. Study subjects were nurses, technicians and nursing assistants who agreed to participate in research. The results indicate that the mode of organization of nursing staff work is focused on procedures and fragmentation of tasks. The lack of human resources, work overload, overcrowding, work dissatisfaction and demotivation are determinants that contribute to this care model. These are aggravating the problems for the child, family and professionals, creating fear, anxiety, anguish, pain and may trigger psychological distress. To overcome this urge adoption of the technology of care guided by the entirety, link, accountability. The construction of nursing care for hospitalized children requires that reflect their professional practice, reorganizing its business processes from the collective work and humanized.

Descriptors: Child hospitalized; Care Nursing; Pediatric Nursing; Work.

\section{RESUMEN}

En el cuidado de los niños hospitalizados deben tratar de construir un proyecto terapéutico compartido y centrado niño y su familia. Este estudio tuvo como objetivo comprender la organización de los trabajos del equipo de enfermería en el cuidado de los niños hospitalizados. La investigación exploratoria de carácter cualitativo de la recogida de datos que se celebró en un hospital de beneficencia en el estado de Pernambuco a través de entrevistas semi-estructuradas en abril y mayo de 2007. Los sujetos de estudio fueron los enfermeros, técnicos y auxiliares de enfermería que aceptaron participar en la investigación. Los resultados indican que el modo de organización de los trabajos del personal de enfermería se centra en los procedimientos y la fragmentación de las tareas. La falta de recursos humanos, sobrecarga de trabajo, el hacinamiento, la insatisfacción y desmotivación de trabajo son los factores determinantes que contribuyen a este modelo de atención. Estos son los problemas agravantes para el niño, la familia y los profesionales, crear miedo, ansiedad, angustia, dolor y pueden desencadenar la angustia psicológica. Enfoque para superar esta instar la adopción de la tecnología de la atención guiada por la totalidad, el vínculo, la rendición de cuentas. La construcción de los cuidados de enfermería para niños hospitalizados requiere que reflejan su práctica profesional, la reorganización de sus procesos de negocio de la obra colectiva y humanizada.

Descriptores: Niño hospitalizado; Cuidados de enfermería; Enfermería pediátrica; El trabajo. 


\section{NTRODUÇÃO}

As transformações que vêm ocorrendo na sociedade trazem repercussões, de maneira significativa, no campo da saúde, tanto no seu objeto como no instrumental teórico-prático em que se apóiam as práticas e na organização da produção em saúde ${ }^{(1)}$.

A concepção do social na área da saúde faz estender o saber para o processo de viver, adoecer e morrer, constituindo em um dos elementos do seu processo de trabalho, exprimindo não apenas as soluções técnicas pertinentes ao trabalho, mas, indicando também como o ser humano se organiza na produção e reprodução de sua existência(2).

A categoria trabalho passou a ser introduzida no campo da saúde para entender o processo saúdedoença e as práticas de saúde em nossa sociedade. O objeto da prática da saúde passou a ser os corpos sociais e não mais os biológicos analisando o processo saúde-doença em suas relações com a estrutura econômica, política e ideológica da sociedade ${ }^{(1)}$.

O trabalho humano nas sociedades capitalistas foi estudado por Marx ${ }^{(3)}$ que conceituou o processo de trabalho e o descreveu a partir da relação de três elementos: a atividade adequada a um fim, isto é o próprio trabalho; a matéria a que se aplica o trabalho, o objeto de trabalho; os meios de trabalho, o instrumental de trabalho.

Na perspectiva marxista, o processo de trabalho humano é um processo de produção e reprodução do homem social, determinado historicamente por meio da produção de bens e serviços compreendidos como um conjunto articulado de momentos indispensáveis ao desencadeamento para a produção intencional de respostas a necessidades estabelecidas na dinâmica social que precisam ser satisfeitas, como necessidades de saúde ${ }^{(4)}$.

Partindo da apreensão dos elementos constituintes do processo de trabalho, foi desenvolvido um profundo raciocínio lógico e dialético para compreender as práticas em saúde, na sua dimensão de trabalho, discutindo e redefinindo a tecnologia, na perspectiva de "organização tecnológica do trabalho"(4).

Como o trabalho em saúde produz homens em relação com outros homens, então, em um dado momento da vida humana, pela lógica marxista desse trabalho, o homem se tornará objeto do trabalho, pois entendemos que ele é a matéria sobre qual o trabalho será realizado.

A saúde é um serviço que se fundamenta em uma inter-relação pessoal muito intensa na qual o consumidor fornece valores de uso necessários ao processo de trabalho, valores de uso esses que vão desde a informação acerca da história que se passou com ele até sua participação no processo terapêutico(5).
Percebendo a saúde como cenário de relação inter-pessoal, precisamos apreender o agente no interior das relações entre seu objeto de intervenção, instrumentos e atividades, como também no interior do processo de divisão do trabalho. Cada agente opera a transformação de um objeto em um produto que cumpre a finalidade, desde o início, como intencionalidade daquele trabalho específico ${ }^{(6)}$.

No entanto, a organização parcelar do trabalho fixa os trabalhadores em uma determinada etapa do projeto terapêutico. O trabalho fracionado faz com que o profissional de saúde se aliene do próprio objeto de trabalho. Desta forma, ficam os trabalhadores sem interação com o produto final da sua atividade laboral, mesmo que tenham dele participado, pontualmente. Como não há interação, não haverá compromisso com resultado do seu trabalho ${ }^{(7)}$.

Por outro lado, ao passo que a divisão técnica introduz o fracionamento de um mesmo processo de trabalho introduz, também, os aspectos de complementaridade e de interdependência entre os trabalhos especializados referentes a uma mesma área de produção. Devem-se considerar, concomitantemente, as dimensões técnica e social da divisão do trabalho, uma vez que toda divisão técnica reproduz em seu interior as relações políticas e ideológicas atinentes às desiguais inserções sociais dos sujeitos ${ }^{(6)}$.

O trabalho parcelar e fragmentado, ao reduzir a ação operária a um conjunto repetitivo de atividades, fixa os profissionais em determinada etapa de certo projeto terapêutico produzindo, dessa forma, alienação.

Podemos destacar, também, que a divisão social que ocorre no trabalho reproduz em parte a divisão de classes sociais dada no âmbito mais geral da sociedade capitalista e tem determinado, na área da saúde, uma divisão técnica que se configura em um acentuado parcelamento do trabalho em saúde e em categorias de trabalhadores com funções, habilidades, qualificação, remuneração e status extremamente diversificados ${ }^{(8)}$.

Nas relações da equipe de enfermagem que trabalha com a criança hospitalizada há outro cenário, no qual o trabalho parcelar e fragmentado absorve a mãe caracterizando como mais um agente do trabalho, pois passa a desenvolver atividades mais simples, alimentando o processo de trabalho.

No entanto, o modo como se organiza o processo de trabalho da equipe responsável pela atenção à saúde da criança, vem delineando um modelo de assistência tecnicista, burocratizado e fragmentado que desconsidera as particularidades que envolvem a hospitalização infantil. Os serviços de saúde, que seguem o modelo de cuidado integral à criança, apresentam um discurso eficaz do ponto de vista ideológico, mas de fato essa efetividade do 
cuidado é dificultada pela escassez de recursos, filosofia de trabalho implantada, falta de sensibilização e instrumentalização dos profissionais, assim, surge novas necessidades no processo de trabalho(9).

Frente a esse cenário, os profissionais que lidam com esses sujeitos - criança e família - devem buscar meios que minimizem os danos que a hospitalização pode trazer para o desenvolvimento da criança, assim como fortalecer o vínculo entre essa e sua família.

Reconhecendo a equipe de enfermagem como elemento importante na construção do projeto de cuidado integral, buscamos compreender como se organiza o trabalho dos profissionais que estão envolvidos no cuidar de crianças hospitalizadas e como a equipe partilha o cuidado com a família, para atender às necessidades que sobressaem dessa relação mãe-filho-equipe.

Portanto, esta investigação teve o objetivo de apreender a organização do processo de trabalho da equipe de enfermagem que está envolvida na assistência à criança hospitalizada.

\section{PERCURSO METODOLÓGI CO}

Pesquisa do tipo exploratória que teve como finalidade desenvolver, esclarecer e modificar conceitos e ideias com vistas à formação de problemas mais precisos ou hipóteses pesquisáveis, objetivando proporcionar uma visão geral do tipo aproximativo acerca de determinado fato ${ }^{(10)}$. Este estudo foi delineado pela abordagem qualitativa, na qual se conhece um nível de realidade trabalhando o universo de significados, sentimentos, motivos, aspirações, crenças, valores e atitude presentes em processos e fenômenos que não podem ser mensurados $^{(11)}$. Para a discussão dos dados empíricos utilizamos a organização tecnológica do trabalho como referencial teórico que investiga conceitualmente a aplicação da teoria marxista do trabalho ao campo da saúde ${ }^{(4)}$.

A pesquisa foi desenvolvida em uma unidade de clínica pediátrica de um hospital de atenção terciária, referente para a região nordeste no atendimento materno-infantil, situado na região metropolitana do Recife-PE. Essa unidade possui um total de 67 leitos, sendo distribuídos por oito enfermarias coletivas com oito ou nove leitos cada, conformando-se em um setor de alta rotatividade. As unidades de internação adotam o sistema de alojamento conjunto pediátrico.

$O$ quadro de profissionais de enfermagem da unidade em estudo é formado por seis enfermeiras e 58 profissionais de nível médio (técnico ou auxiliar de enfermagem). Os participantes do estudo foram profissionais que compõem a equipe de enfermagem que trabalham na referida unidade. O critério de inclusão dos sujeitos no estudo foi o de estar lotado há mais de um ano na unidade possuindo, assim, experiência no seu local de trabalho e, portanto, mais elementos para apreensão de seu processo de trabalho e aceitar participar da pesquisa.

A coleta de dados empíricos foi realizada nos meses de abril e maio de 2007 por meio da técnica de entrevista semi-estruturada. As mesmas foram gravadas, após aceite dos entrevistados, a fim de captar as falas dos sujeitos da pesquisa. Para encerrarmos a coleta de material empírico utilizamos o critério de obtenção de respostas aos nossos questionamentos. Assim, participaram deste estudo três enfermeiras, três auxiliares e duas técnicas de enfermagem.

Para a análise dos dados adotamos a técnica de análise temática ${ }^{(11)}$ que consiste na descoberta dos núcleos de sentido que compõem uma comunicação, cuja presença ou frequência signifiquem alguma coisa para o objetivo analítico visado. Partindo da análise, pudemos agrupar os dados empíricos nos seguintes temas: sobrecarga de trabalho, fragmentação do cuidado e percepções dos sujeitos quanto ao seu trabalho em relação às condições laborais.

Para a realização do presente estudo, foi considerado o que preceitua a Resolução № 196/96 do Conselho Nacional de Saúde/Ministério da Saúde ${ }^{(12)}$. Portanto, o projeto de pesquisa foi encaminhado ao Comitê de Ética em Pesquisa com Seres Humanos da instituição onde foi realizado o estudo para apreciação, o qual recebeu parecer favorável (Parecer no 910). Após aceitar participar da pesquisa, os sujeitos assinaram o Termo de Consentimento Livre e Esclarecido. Para garantir o anonimato dos sujeitos do estudo e preservar a identidade das pessoas, utilizamos as iniciais $\mathrm{E}$ para as enfermeiras participantes do estudo e $A E$ para as auxiliares e TE para as técnicas de enfermagem.

\section{Organização tecnológica do trabalho de enfermagem na assistência à criança hospitalizada}

Por meio deste estudo, percebemos que o trabalho da equipe de enfermagem que atua no cuidado à criança hospitalizada se mostra semelhante ao que tem sido evidenciado na literatura que abrange o processo de trabalho em saúde.

Como sujeito que perfaz o cenário da saúde, a enfermagem vivencia as intempéries que envolvem todo e qualquer processo de trabalho, a saber, excesso de carga no trabalho e fragmentação do cuidar. Como sujeito ativo do trabalho em saúde, os profissionais de enfermagem se percebem inseridos no processo de construção de um projeto terapêutico e vivenciam os problemas que permeiam seu cotidiano na assistência à criança hospitalizada.

\section{Sobrecarga de trabalho}

Diante da apresentação da unidade em estudo inferimos que tal magnitude pode interferir 
diretamente no trabalho de enfermagem, tanto no que tange à administração de pessoal, assim como na administração da assistência de enfermagem, pois reconhecemos, por meio das falas, que a quantidade de profissionais existente é aquém da necessidade da unidade, comprometendo assim o processo de trabalho da equipe.

Eu acho que é um setor muito grande para poucos enfermeiros [...] se fosse mais enfermeiras, eu acho que nem duas dava $(E, 1)$;

Não tem uma supervisão geral da gerente, não tem como ela fazer $(E, 2)$;

A gente sabe que isso aqui não é fácil [...] pela demanda dos pacientes que existe aqui [...] eu acho que se tipo fosse duas enfermeiras, a gente dava uma assistência considerada boa $(E, 3)$.

Não encontramos na literatura norma que define a quantidade de leitos ou tamanho de unidades de alojamento conjunto pediátrico. No entanto, analisando criticamente percebemos os entraves e dificuldades que uma unidade desse porte traz para a administração de pessoal bem como para a administração da assistência de enfermagem.

Além desse problema apresentado pelos sujeitos da pesquisa, também identificamos a necessidade de repensar a sobrecarga que esses profissionais vivenciam no cotidiano do trabalho. A assistência de enfermagem prestada por um profissional submetido a uma rotina exaustiva apresenta-se vulnerável em diversos aspectos, podendo interferir na finalidade de seu processo de trabalho. Em todas as entrevistas realizadas, os profissionais teceram relatos a respeito da sobrecarga de trabalho.

Só uma auxiliar ou técnico para oito crianças ou nove crianças, então, e aí a gente tem que daí fazer assim, se virar em duas (TE, 1);

A maioria das auxiliares acha muita coisa porque são muitos meninos, muitos procedimentos ( $A E, 1)$;

A gente fica com nove pacientes, uns ficam sozinhos, a gente fica super carregado, fica super corrido para gente $(A E, 2)$.

Nosso estudo corrobora os dados encontrados em outra pesquisa ${ }^{(13)}$ na qual foi evidenciado que a quantidade de enfermeiros lotados por instituição, em relação à carga de trabalho, é pequena levando a uma sobrecarga no trabalho. Desvendando os prejuízos que essa sobrecarga de trabalho traz para a assistência de enfermagem, em alguns depoimentos ficou evidente que o cuidado prestado revela um déficit ou uma descontinuidade, uma vez que a relação demanda-funcionários é desproporcional:

A enfermeira, a parte de assistência, eu acho que ela acaba fazendo muito pouco porque pela demanda né [...] a enfermeira fica com essa parte de assistência né, de evoluir, de fazer a visita, de fazer o exame físico que muitas vezes a gente acaba não fazendo todos porque é humanamente impossível $(E, 2)$.

Salientamos que, além dos aspectos anteriormente abordados, a sobrecarga de trabalho imprime uma forma de organização da assistência na qual algumas ações privativas do enfermeiro tem sido realizadas por profissionais do nível médio. A falta de reorganização das atribuições dos enfermeiros sobrecarregam o seu dia-a-dia fazendo com que passe a delegar suas atribuições privativas aos técnicos e auxiliares de enfermagem ${ }^{(14)}$. Na unidade em estudo essa também tem sido a forma de conduzir o trabalho, conforme explicitado nos depoimentos a seguir:

Eles (técnicos/auxiliares) aspiram, passam sonda naso e oro quem passa são eles porque não tem condição da gente passar, uma enfermeira só saí passando trezentas sondas, num setor com essa quantidade [...] a burocrata do material descartável, ela abre os horários das medicações $(E, 1)$;

A (sonda) naso quando o menino é maior eles chamam a enfermeira para que passe, mas até pela demanda é eles que fazem [...] muitas vezes a gente não está disponível para fazer aspiração de vias aéreas e de traqueóstomo, a gente acaba delegando para que o auxiliar faça porque não tem como estar a cada duas horas na mesma enfermaria $(E, 2)$.

Ao delegar suas atribuições privativas aos auxiliares e técnicos de enfermagem, o enfermeiro não tem refletido sobre o desencadeamento dessa conduta. $\mathrm{Na}$ instituição em estudo, deparamo-nos com uma forma de organização do trabalho que gera conflitos entre os profissionais da equipe de enfermagem, pois foi verificado que os técnicos e auxiliares realizam atividades que fazem parte da atribuição do enfermeiro.

\section{Fragmentação do cuidado}

O trabalho da enfermagem, que deve ser pautado por um cuidar integral ao paciente, está sendo fragmentado no modo de organização da assistência adotado na unidade em estudo. Identificamos a centralidade na divisão social e técnica do trabalho cuja finalidade é aumentar a produtividade do serviço e a especialização dos funcionários executores de funções específicas. Assim, enquanto um trabalhador de enfermagem realiza cuidados básicos de alimentação e higiene à criança, outro administra os medicamentos e outro faz os curativos e demais cuidados.

Em nosso estudo, deparamo-nos com a lógica taylorista que fragmenta o cuidar e torna o trabalho similar aos que ocorrem em linhas de montagem, cuja especialização restringe-se a uma determinada tarefa em detrimento do todo do processo de trabalho ${ }^{(15)}$.

Medicação injetável, pelo menos nesse setor, tem uma funcionária, né, uma técnica que fica responsável por essa administração $(E, 2)$;

Ela vai administrar, vai preparar toda a medicação e ela administra nos horários, é uma só para sessenta 
e sete, então ela começa sempre antes do horário, a medicação de dez ela começa de nove e meia e termina de onze $(E, 1)$.

O trabalho parcelar e fragmentado ao reduzir a ação operária a um conjunto repetitivo de atividades, fixa os profissionais em determinada etapa do projeto terapêutico produzindo alienação ${ }^{(15)}$. Tal concepção pode ser identificada no depoimento a seguir:

O trabalho aqui no dia-a-dia é muito estressante, porque olhe, é muita medicação [...] aqui deveria ser uma pessoa do soro, uma da medicação e outra da enfermaria $(A E, 3)$.

A prática de enfermagem realizada nessa unidade ratifica os discursos teóricos, mostrando que o processo de trabalho da equipe que atua no cuidado à criança hospitalizada apresenta-se parcelar e pormenorizado, evidenciando a visão fragmentada que os profissionais têm dos sujeitos.

Em relação a essa forma fragmentária de organização do processo de trabalho da enfermagem na unidade em estudo, ressaltamos que a manipulação e a administração de medicamento é tarefa complexa requerendo dos profissionais, responsabilidade, conhecimentos farmacológico, de fisiologia e anatomia, além da habilidade técnica em si e concentração no momento do preparo e administração dos medicamentos.

O despreparo dos profissionais na administração de medicamentos tem sido objeto de estudo ${ }^{(16)}$ que tem demonstrado as sérias conseqüências ao paciente, muitas vezes debilitantes, desencadeando reações indesejadas, como complicações advindas de procedimentos técnicos inadequados ou incorretos decorrentes dos erros na medicação.

Como fruto dessa fragmentação, identificamos o quanto essa prática poderia interferir na ação dos demais integrantes da equipe, já que eles estariam susceptíveis a perder a habilidade de preparar e administrar medicações injetáveis, bem como o responsável pela medicação ficaria limitado a essa prática perdendo a habilidade nas demais ações individualmente. Assim, ambos perdem o contexto integral do conjunto que compõe o cuidar à criança hospitalizada. Esse foi um dos entraves apontados pelas participantes da pesquisa, embora haja divergências, conforme explicitado nos relatos a seguir.

Eu acho muito importante ter uma menina da injetável que ela fica responsável só por aquilo [...] eu nunca vi ninguém da injetável sair [...] os rodízios ocorrem nas enfermarias, na injetável nunca ocorre, sempre são as mesmas $(E, 1)$.

Você sabe que tem uma pessoa responsável, que está responsável por tudo, então toda essa parte de injetável você vai realmente recorrer a ela em qualquer dificuldade né, mas eu acho também que é de muita responsabilidade para uma pessoa só, né, como é que uma pessoa só fica responsável por todas as medicações, que eu acho que até poderia ser dividido, eu não sei também se isso dificulta a prática dos outros que fica limitado a só fazer as medicações orais e acaba perdendo um pouco da prática [...] eu acho que tem essa dificuldade porque limita, limita os outros funcionários $(E, 2)$.

Além dessas questões, devemos lembrar que são sessenta e sete crianças internadas nessa unidade e que existe uma padronização no horário de administração de medicação. Como apenas um profissional é responsável por essa tarefa, há sobrecarga de trabalho em torno de uma atividade tão complexa como é a administração de medicamentos em pediatria. A atenção e concentração exigidas para o desenvolvimento dessa atividade são muito grandes, pois as dosagens são fracionadas de acordo com o peso de cada criança requerendo diluições e rediluições. Além do risco de haver erros no preparo da medicação, há também, riscos de erros na administração, especialmente quanto ao cumprimento dos horários prescritos.

Em um ambiente onde as responsabilidades não são compartilhadas entre os sujeitos que operam na assistência de enfermagem gera uma inquietação sobre quais são os limites da atuação dos sujeitos do cuidado, uma vez que as especificidades do trabalho da enfermagem são desprezadas. Então, a rotina segue no setor, enquanto a reflexão tarda para aproximar-se da equipe que continua sem delimitar as responsabilidades nem tampouco integrar a assistência.

\section{Percepções dos sujeitos quanto ao seu trabalho em relação às condições laborais}

Embora as condições de trabalho não sejam as almejadas pelos profissionais, eles referem trabalhar com dedicação para dar a melhor assistência possível mesmo com suas limitações, sejam elas de retribuição financeira ou condições laborais.

A gente vai dar o máximo que a gente pode dar que a gente não está só limitado a um ou a outro paciente, mas sim sessenta e sete $(A E, 1)$.

É como se você corresse muito para dar conta da quantidade da demanda e muitas vezes você não consegue, não consegue fazer isso, e você luta, é como se você estivesse no mar né, lutando, tentando nadar e fazendo a sua parte que acaba sendo a mínima perto do que seria necessário $(E, 2)$.

Embora os profissionais estejam motivados pelo trabalho em si, nessas falas percebemos os sentimentos de frustração que os mesmos expressam ao não conseguir prestar assistência em decorrência da demanda de pacientes em relação à escassez de recursos humanos.

Os fatores que motivam os profissionais envolvidos no cuidar nessa unidade relacionam-se ao trabalho em si, ao significado que este tem para a equipe de saúde. 
Eu acho que a enfermagem, o trabalho da enfermagem é primordial, eu acho que a enfermagem, ela é tudo dentro de um hospital né, a enfermagem está ali para fazer acontecer realmente [...] e é gratificante [...] se eu tivesse que fazer faculdade novamente seria de enfermagem de novo $(E, 2)$.

O prazer do trabalho está na melhora do paciente, na sensação de ter respondido à finalidade de seu trabalho. Ao mesmo tempo em que há idealização do trabalho, há também a frustração pelo não reconhecimento, pela desvalorização. Essa idealização, além de ser uma construção histórica pode servir também como estratégia defensiva, assim, as profissionais de enfermagem preservam um lugar onde se sintam úteis e de alguma forma valorizadas $^{(17)}$.

Por outro lado, podemos perceber os sentimentos negativos expressados por uma enfermeira no que tange à valorização de seu trabalho e à humanização no ambiente laboral:

Eu recebo muito mal para estar me desgastando com 67 pacientes [...] é tudo, a gente faz de tudo, o povo não reconhece $[\ldots]$ eu acho que eu não gosto, não me sinto realizada enquanto enfermeira [...] a gente devia ser mais valorizado na profissão [...] estou trabalhando aqui sob uma pressão muito grande [...] eu já saí daqui chorando [...] eu acho que a desvalorização é muito grande [...] a gente faz tudo aqui apesar de ninguém valorizar [...] é terrível, eu não gosto [...] eu acho que não tem material suficiente, não tem funcionário suficiente, tudo se torna um problema [...] eu não sinto realizada enquanto enfermeira [...] eu acho que a gente devia ser mais valorizado na profissão da gente [...] elas (auxiliares) não têm estímulo para trabalhar aqui, não têm estímulo para trabalhar porque ganham mal, trabalham muito, e não têm condições, é totalmente insalubre aqui né [...] se eu fosse auxiliar eu não trabalharia aqui jamais [...] as auxiliares não têm lugar para dormir [...] você vê aquilo e fica calada, você não pode fazer nada, você não manda no hospital $(E, 1)$.

Assim, as atividades dos profissionais de saúde geram tensões devido às prolongadas jornadas de trabalho, ao número limitado de profissionais e ao desgaste psicoemocional nas tarefas em ambiente hospitalar. Os profissionais de enfermagem são expostos a ambientes de trabalho intensamente insalubre e, por estarem submetidos a condições de trabalho precarizadas e à baixa qualidade de vida, são expostas a situações nas quais a manutenção da saúde está prejudicada(17).

Sabe-se que as precárias condições de trabalho geram sofrimento, pois o trabalhador se vê importante em relação à qualidade da assistência ao cliente, gerando insatisfação no trabalho e ainda um rompimento no seu processo de trabalho(18).
Para que os trabalhadores de saúde possam exercer a profissão com honra e dignidade, respeitar o outro em sua condição humana, necessitam manter sua condição humana também respeitada, ou seja, trabalhar em adequadas condições, receber uma remuneração justa e o reconhecimento de suas atividades e iniciativas ${ }^{(19)}$.

A humanização é um dos fatores desencadeantes do processo de trabalho reflexivo e da assistência prestada nos serviços de saúde. Assim, percebe-se a importância que esse fato traz para o trabalho da enfermagem que está envolvida no cuidar da criança hospitalizada que demanda um cuidar diferenciado, um cuidar destinado à célula familiar.

O hospital é um ambiente que desencadeia sentimentos conflitantes nos trabalhadores que nele atuam. Ora esses sentimentos são frustrantes, desgastantes (a piora do quadro clínico da criança), ora são estimulantes e gratificantes (recuperação da saúde da criança). Esses aspectos aliados às más condições de trabalho, geralmente desencadeiam angústia e insatisfação podendo levar a prejuízos tanto à saúde física, quanto à saúde mental dos trabalhadores.

O desafio da enfermagem consiste em reorientar sua prática profissional na perspectiva de transformação do seu processo de trabalho, no sentido de diminuir o impacto da sua divisão social e da sua organização que interferem no desgaste físico e psíquico do trabalhador, buscando respeitar seu direito de viver e trabalhar em condições econômicas e sociais dignas ${ }^{(20)}$.

\section{CONSI DERAÇÕES FI NAIS}

O modo como está organizado o processo de trabalho, na unidade do estudo, traz prejuízos ao serviço de enfermagem, uma vez que esse fica sem visibilidade diante de uma instituição que segue os padrões taylorista, tecnicista e biologista no atendimento à saúde. Essa ótica acerca da organização do trabalho da enfermagem imprime um direcionamento cada vez mais fragmentário e parcelar inviabilizando a lógica do cuidado ampliado em saúde.

Diante disso, mostra-se emergente rever a dinâmica do funcionamento do serviço, visto que esse se dá em um ambiente em que a sobrecarga de trabalho e a fragmentação do cuidado tem sido determinantes para a construção de atores sociais alienados.

As atividades dos profissionais de saúde geram tensões devido às prolongadas jornadas de trabalho, ao número limitado de profissionais e ao desgaste psicoemocional nas tarefas realizadas em ambiente hospitalar. Podemos, ainda, apontar essa sobrecarga como um dos fatores da fragmentação do trabalho da enfermagem, pois desencadeia um modo de 
organizar o trabalho no qual as tarefas são divididas de forma taylorista visando alcançar a produtividade almejada, obstaculizando, assim, a superação do modelo tradicional por um modelo ampliado de atenção à saúde.

Assim, urge a necessidade de refletir acerca dessas situações a fim de se construir coletivamente, enfermagem, equipe de saúde e gestão do serviço e familiares, meios que reestruturem a prática assistencial à saúde da criança visando melhores condições de trabalho e diminuição dos efeitos danosos à saúde física e mental desses profissionais, para que a qualidade da assistência de enfermagem seja garantida.

\section{REFERÊNCI AS}

1. Rocha SMM, Almeida MCP. O processo de trabalho da enfermagem em saúde coletiva e a interdisciplinaridade. Rev Latino-am Enfermagem. 2000; 8(6): 96-101.

2. Silva ATMC, Barros S. O trabalho de enfermagem no Hospital Dia na perspectiva da reforma psiquiátrica em João Pessoa - Paraíba. Rev. esc. enferm. USP. 2005; 39(3): 310-16.

3. Marx K. O capital. Rio de Janeiro: Brasiliense; 1996.

4. Mendes-Gonçalves RB. Práticas de saúde: processo de trabalho e necessidades. São Paulo: Centro de Formação dos Trabalhadores em Saúde da Secretaria Municipal de Saúde; 1992.

5. Nogueira RP. O trabalho em serviços de saúde. In: Santana JP, editor. Desenvolvimento gerencial de unidades básicas do Sistema Único de Saúde (SUS). Brasília: OPAS; 1997.

6. Peduzzi M. Equipe multiprofissional de saúde: conceito e tipologia. Rev Saude Publica. 2001;35(1): 103-9.

7. Franco TB, Bueno WS, Merhy EE. O acolhimento e os processos de trabalho em saúde: o caso de Betim, Minas Gerais, Brasil. Cad. Saúde Pública. 1999; 15(2): 345-53.

8. Kantorski, LP. As transformações no mundo do trabalho e a questão da saúde. Rev Latino-am Enfermagem. 1997;5(2): 5-15.

9. Gaíva MAM, Scochi CGS. Rev. Processo de trabalho em saúde e enfermagem em UTI neonatal. Rev Latino-am Enfermagem. 2004; 12(3): 469-76.

10. Gil, AC. Métodos e técnicas de pesquisa social. São Paulo: Atlas; 2002.

11. Minayo, MCS. O desafio do conhecimento: pesquisa qualitativa em saúde. São Paulo: Hucitec; 2008.

12. Ministério da Saúde; Conselho Nacional de Saúde. Resolução № 196/96 - Normas regulamentadoras de pesquisa envolvendo seres humanos. Brasília (Brasil): Ministério da Saúde; 1996.

13. Batista AAV, Vieira MJ, Cardoso NCS, Carvalho
GRP. Fatores de motivação e insatisfação no trabalho do enfermeiro. Rev. esc. enferm. USP. 2005; 39(1): 85-91.

14. Silva BM, Lima FRF, Farias FSAB, Campos ACSC. J ornada de trabalho: fator que interfere na qualidade da assistência de enfermagem. Texto-Contexto Enferm. 2006; 15(3): 442-8.

15. Malta DC, Merhy EE. A micropolítica do processo de trabalho em saúde - revendo alguns conceitos. Rev. Rene. 2003; 7(1):61-6.

16. Carvalho VT, Cassiani SHB. Erros na medicação: análise das situações relatadas pelos profissionais de enfermagem. Medicina (Ribeirão Preto). 2000; 33(2): 222-30.

17. Elias MA; Navarro VL. A relação entre o trabalho, a saúde e as condições de vida: negatividade e positividade no trabalho das profissionais de enfermagem de um hospital escola. Rev Latino-am Enfermagem. 2006; 14(4): 517-25.

18. Medeiros MM, Ribeiro LM, Fernandes SMBA, Veras VSD. Condições de trabalho e enfermagem: a transversalidade do sofrimento no cotidiano. Rev. Eletr. Enf. [Internet]. 2006 [cited 2008 mar 27]. Available from: http://www.fen.ufg. br/revista/revista8_2/v8n2a08.htm.

19. Backes DS, Lunardi VL, Lunardi WDFilho. A humanização hospitalar como expressão da ética. Rev Latino-am Enfermagem. 2006; 14(1): 132-5.

20. Cavalcante CAA, Enders BC, Menezes RMP, Medeiros SM. Riscos ocupacionais do trabalho em enfermagem: uma análise contextual. Ciênc. cuid. saúde. 2006; 5(1):88-97.

Artigo recebido em 12.08.08.

Aprovado para publicação em 30.06.09.

Artigo publicado em 30.09.09. 